\title{
O HAITI E A ALTERNATIVA MIGRATÓRIA ${ }^{1}$
}

\section{HAITI AND THE MIGRATORY ALTERNATIVE}

\author{
HAITÍ Y LA ALTERNATIVA MIGRATORIA
}

\author{
Alex Dias de Jesus \\ Instituto Federal do Piauí \\ alexdias@ifpi.edu.br \\ Jones Dari Goettert \\ Universidade Federal da Grande Dourados \\ jonesgoettert@ufgd.edu.br
}

\section{RESUMO}

Este artigo objetiva traçar um panorama das migrações haitianas para diversos destinos do mundo, em destaque para o continente americano. Transformado em país mais pobre do continente e imerso em uma contínua crise que mistura instabilidade política, precariedade econômica, ingerência estrangeira e desastres ambientais, o Haiti tornou-se incapaz de prover dignamente a sua população dos direitos humanos mais básicos como saúde e educação gratuitas. Frente a um quadro tão complexo, milhões de haitianos buscam na migração internacional alternativas para a melhoria das condições de vida, inclusive dos familiares que permanecem no país. Com base em um levantamento bibliográfico diversificado, foi possível identificar que há mais de um século a migração internacional vem sendo a saída encontrada por parte significativa da população. No século XXI, frente às restrições de entrada no Norte Global, os haitianos incorporam países da América do Sul como novos destinos.

Palavras-chave: Haiti. Migração Internacional. Espaço transnacional. Trabalho. Remessas.

\section{ABSTRACT}

This article aims to provide an overview of Haitian migrations to various destinations in the world, especially the American continent. Transformed into the poorest country on the continent and plunged into a continuous crisis that mixes political instability, economic

\footnotetext{
${ }^{1}$ Este artigo é resultado da pesquisa de doutorado do autor, realizada no Programa de Pós-Graduação em Geografia da Universidade Federal da Grande Dourados (UFGD), com o título "Redes da migração haitiana no Mato Grosso do Sul" (2020).
} 
precariousness, foreign interference and environmental disasters, Haiti has become incapable of dignifiedly providing its population with the most basic human rights such as health and education free. Faced with such a complex situation, millions of Haitians are looking to international migration for alternatives to improve their living conditions, including family members who remain in the country. Based on a diversified bibliographic survey, it was possible to identify that for over a century international migration has been the solution found by a significant part of the population. In the 21 st century, faced with restrictions on entry into the Global North, Haitians are incorporating South American countries as new destinations.

Keywords: Haiti. International Migration. Transnational space. Work. Remittance.

\section{RESUMEN}

Este artículo tiene como objetivo proporcionar una descripción general de las migraciones haitianas a varios destinos en el mundo, especialmente al continente americano. Transformado en el país más pobre del continente y inmerso en una crisis continua que mezcla inestabilidad política, precariedad económica, injerencia extranjera y desastres ambientales, Haití se ha vuelto incapaz de brindar dignamente a su población los derechos humanos más básicos como la salud y educación gratis. Ante una situación tan compleja, millones de haitianos buscan en la migración internacional alternativas para mejorar sus condiciones de vida, incluidos los familiares que permanecen en el país. A partir de un estudio bibliográfico diversificado, se pudo identificar que durante más de un siglo la migración internacional ha sido la solución encontrada por una parte importante de la población. En el siglo XXI, ante las restricciones de entrada al Norte Global, los haitianos están incorporando a los países de América del Sur como nuevos destinos.

Palabras clave: Haiti. Migración Internacional. Espacio transnacional. Trabajo. Remesas.

\section{INTRODUÇÃO}

A migração internacional é uma marca profunda do Haiti. Há mais de um século os haitianos recorrem à migração como alternativa ao precário quadro socioeconômico vigente e buscam, por meio da inserção laboral e educacional fora do país, formas de ascensão social tanto para os que migram quanto para os que permanecem. Uma das características marcantes

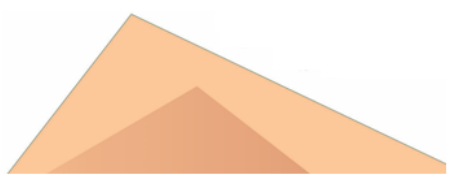


dessa migração, verificada em vários fluxos em diferentes tempos e espaços, é a grande vinculação daqueles que migram com as famílias e comunidades de origem.

De maneira paradoxal, a globalização, desde as fases iniciais da colonização até o período atual, deslocou o Haiti para a periferia através da Divisão Internacional do Trabalho e ofereceu condições - predominantemente precárias - para a inserção dos migrantes haitianos como trabalhadores necessários nas economias desenvolvidas e subdesenvolvidas, ocupando um lugar bem marcado na parte inferior da hierarquia social. Como exemplo, os haitianos estiveram empregados nos canaviais da República Dominicana e de Cuba, no setor hoteleiro das Bahamas, e mais recentemente na construção civil e nos frigoríficos do Brasil.

O passado do Haiti como colônia francesa contribuiu para que a província do Quebec, no Canadá, e os atuais departamentos ultramarinos franceses de Martinica, Guadalupe, San Martin e Guiana Francesa e a própria França se transformassem em destinos dos migrantes haitianos. Por outro lado, a influência dos Estados Unidos no Caribe, especialmente após a ocupação americana no Haiti, entre 1915-1934, também influenciou para que grandes grupos se estabelecessem em cidades como Miami, Nova York e Boston e em suas respectivas regiões metropolitanas.

A localização do Haiti, no centro do mar do Caribe, contribuiu para que além dos destinos prioritários, outros intermediários fossem alcançados em uma migração por etapas. Várias ilhas do Caribe passaram a receber migrantes haitianos que pretendiam se estabelecer temporariamente antes de ingressar em países como Estados Unidos, França e Canadá. Essa estratégia, nem sempre concretizada, ampliou o espaço social haitiano para além das fronteiras do Estado-nação.

Como uma constante, a migração haitiana segue como alternativa viável para a reprodução social e mobilidade econômica. É por isso que, de maneira quase ininterrupta, os haitianos seguem apostando na migração, acrescentando destinos na diáspora que se iniciou há mais de um século. A América do Sul, especialmente países como Brasil e Chile, tem se constituído como uma recente extensão do espaço transnacional haitiano através das relações sociais dos migrantes e não migrantes entre origem e destinos. 
Recentemente, impactados pela deterioração das condições de vida no Brasil, muitos daqueles que haviam aqui chegado anos antes passaram a migrar em direção aos Estados Unidos. Um projeto nem sempre bem-sucedido, obrigando milhares deles a permanecerem nas cidades da fronteira norte do México. Em 2021, além da saída massiva de haitianos do Brasil e do Chile, muitos outros saídos diretamente do Haiti se somaram àqueles que permanecem no México há alguns anos para, uma vez mais, tentarem ingressar nos Estados Unidos.

Frente a isso, o objetivo deste artigo é apresentar um panorama da migração haitiana pelo mundo, argumentando que a saída do país é uma alternativa de sobrevivência apresentada para homens e mulheres, sobretudo os mais jovens. Para isso, buscamos auxílio em um levantamento bibliográfico diversificado sobre investigações realizadas nos diversos destinos dessa intensa e contínua migração. Espera-se, com isso, que o leitor possa compreender que as raízes da migração estão fortemente assentadas no desenvolvimento desigual.

\section{A SAÍDA MIGRATÓRIA: OS HAITIANOS PELO MUNDO}

O Haiti foi marcado pela grande presença estrangeira no país. Pouco tempo depois da independência, a imposição das dívidas vinculou a produção interna às necessidades das potências e submeteu o Haiti à dependência internacional. Embora a ocupação dos Estados Unidos tenha se efetivado em 1915, antes disso, já era grande a influência norte-americana nas terras caribenhas através de empresas agropecuárias. Por meio delas surgem as primeiras grandes migrações de haitianos para outros países do Caribe, principalmente Cuba e República Dominicana.

Transformado em país mais pobre do continente americano, é dele que saem, há mais de um século, os trabalhadores e trabalhadoras mais pauperizados que serão recrutados (ou não) em diversos países da região. Para os que dispõem de melhores condições financeiras, o acesso aos Estados Unidos, Canadá e França é prioritário. Para os demais, além desses 
destinos, outros atravessamentos intermediários funcionam como estágios a serem cumpridos. É assim que alcançam o México, a República Dominicana ou a Guiana Francesa. A maioria permanece sem alcançar o sonho da "grande diáspora", mas não regressam em definitivo para o Haiti.

Enquanto fenômeno de grande dimensão e continuidade no tempo, a mobilidade haitiana assume padrões variados desde o início do século XX. O processo migratório está intimamente ligado à história do Haiti. Postos em movimento, milhões de haitianos expandiram o espaço desse país muito além de suas fronteiras demarcadas, produzindo um espaço transnacional através de variados vínculos. Mais do que os números, as relações entre os diferentes destinos e o Haiti, materializadas pelos sujeitos em mobilidade, lançam luz na compreensão desse processo.

Segundo Regine Jackson (2011), os estudiosos do transnacionalismo acreditam que o geógrafo haitiano Georges Anglade, ainda na década de 1970, foi o primeiro a usar o termo "décimo departamento" para descrever a província externa do Haiti, composta por migrantes, exilados e refugiados que viviam no exterior. Era o início da conceituação do que mais tarde ele chamaria de "novo espaço haitiano" para se referir à diáspora, a ampliação do espaço haitiano feita através das migrações, sua manutenção e recriação a partir de variados fluxos, conectando distintos locais de destino e de passagem com os de origem.

No contexto revolucionário do Haiti no início do século XIX, alguns colonos fugiram e levaram consigo negros escravizados para a vizinha Cuba. Os primeiros colonos francohaitianos começaram a chegar nas províncias de Baracoa, Guantánamo e Santiago de Cuba em 1789, mas em número ainda reduzido. Em 1793, cerca de 2.000 colonos brancos fogem para Cuba, República Dominicana e Estados Unidos (MALEMBE, 2013). Como já tinham experiência no manejo dos cafezais, esses colonos transformaram-se na vanguarda econômica das regiões onde se estabeleceram, principalmente nas franjas montanhosas de Sierra Maestra e na Cordilheira de Nipe-Sagua-Baracoa, locais com terras mais baratas (MACHADO; LORES, 2014).

Esse primeiro fluxo não teve continuidade durante o século XIX. As autoridades coloniais cubanas passaram a impedir a entrada de haitianos para evitar a propagação das 
ideias revolucionárias trazidas pelos negros e mulatos livres ${ }^{2}$. Já estabelecidos na ilha de Cuba, os senhores cuidaram de evitar possíveis revoltas, reduzindo castigos corporais mais severos, permitindo festejos e a compra da liberdade para alguns (MACHADO; LORES, 2014). Desse modo, a migração haitiana para Cuba diminuiu até o fim daquele século, voltando a aumentar nas primeiras três décadas do século $\mathrm{XX}$, com outro perfil e outras características.

De acordo com Machado e Lores (2014), em 1889, a empresa norte-americana United Fruit Company iniciou suas atividades na região cubana de Banes, mas enfrentou escassez de mão de obra local para a construção da usina e das vias férreas. A partir desse momento, inicia-se um fluxo migratório de antilhanos, sobretudo de haitianos e jamaicanos, tendo o primeiro grupo chegado à cidade em 1900. Nos anos seguintes, a companhia manteve a contratação de migrantes, na maioria das vezes de maneira ilegal.

Os braceros, como eram denominados, configuravam uma migração sazonal. Anualmente eram recrutados nas áreas rurais do Haiti e da Jamaica, embarcados para Cuba, onde permaneciam durante os meses da colheita da cana-de-açúcar, principalmente, mas também trabalhavam em cafezais e fazendas de algodão. A contratação dessa mão de obra era vantajosa pois era barata, altamente produtiva, além de não demandar um vínculo empregatício estável, sendo dispensada e devolvida aos seus países no período de entressafra.

Os fluxos ficaram conhecidos, de modo pejorativo, como "haitianadas" e referiam-se aos trabalhadores que se deslocavam principalmente da costa sul do Haiti para o leste de Cuba. "Este tráfico de braceros entre Haiti e Cuba esteve controlado por empreiteiros haitianos, utilizados pelas companhias norte-americanas, que viam nesses homens e mulheres mão de obra barata e disponível aos seus interesses" (MACHE; LIMONTA, 2007, p. 2, tradução nossa). De acordo com Pichardo (1973), em 1912, entraram 1.400 haitianos em Cuba, entre 1913 e 1921, 81.000 e entre 1921 e 1930, 114.495.

A partir desse momento, a migração diminuiu significativamente. A depressão econômica dos anos 1930, as flutuações no preço do açúcar e a crescente rejeição pelos

\footnotetext{
${ }^{2}$ A Revolução Haitiana ocorreu entre 1791 e 1803, com a declaração de independência da França em 1 de janeiro de 1804. Ainda no curso da Revolução, em 1793, os haitianos declararam o fim da escravidão.
} 
trabalhadores cubanos, contribuíram para a criação de decretos que impediram a entrada e expulsaram milhares de antilhanos, sendo a maioria haitianos, ainda no ano de 1931. Apesar da proibição, os braceros continuaram a chegar até 1961 para trabalhar nas lavouras de café (JOSEPH, 2015).

Embora majoritariamente sazonal, gradativamente a população haitiana foi permanecendo em Cuba, dando origem a comunidades nas atuais províncias de Camaguey, Las Tunas, Holguín, Granma, Santiago de Cuba e Guantánamo. Começaram a agrupar-se em torno da língua, da religião e de outros costumes trazidos do Haiti, como forma de enfrentar as dificuldades de adaptação. "Isto lhes permitiu sustentar uma identidade entre seus membros e, a sua vez, constituir elementos de alteridade ao proporcionar a diferenciação como meio de reafirmação ou autodefinição de si mesmos" (MACHE; LIMONTA, 2007, p. 3, tradução nossa). Para essas autoras, as comunidades haitianas, em consequência dos processos de transculturação, transformaram-se em comunidades haitiano-cubanas, originando novas características etnoculturais, mudança nas atividades econômicas, bilinguismo, mobilidade para zonas urbanas, dentre outras.

Alguns autores defendem que, com a Revolução Cubana em 1959 e as transformações políticas e econômicas provenientes dela, os haitianos passaram a ter os mesmos direitos que os cubanos e assim suas influências foram visibilizadas gerando processos de transculturação e diminuíram sua marginalização (MALEMBE, 2013; MACHE; LIMONTA, 2007).

Joseph (2015) afirma que, em 1944, estimava-se em cerca de 80.000 o número de haitianos residentes em Cuba. Baptiste e Vieira (2016), apontam a existência de mais de 200.000 na década de 2010. Esse acréscimo se deve às grandes saídas nos últimos anos da ditadura Duvalier, na instabilidade decorrente do golpe de estado de 2001 e mais recentemente, na saída pós terremoto de 2010. Por situar-se a cerca de 100 quilômetros do Haiti, muitos haitianos enxergam em Cuba uma alternativa de destino ou de passagem e se arriscam na travessia em frágeis embarcações. Em 2011, por exemplo, 38 pessoas morreram após o naufrágio de uma embarcação na costa de Guantánamo ${ }^{3}$.

\footnotetext{
3 Naufrágio em Cuba mata 38 emigrantes haitianos. http://veja.abril.com.br/mundo/naufragio-em-cuba-mata-38emigrantes-haitianos/
} 
Também nas primeiras décadas do século XX inicia-se a contratação de braceros para as áreas canavieiras da República Dominicana. Assim como em Cuba, a carência de mão de obra foi suprida com o trabalho sazonal de milhares de antilhanos, inicialmente vindos das ilhas caribenhas de língua inglesa, mas a grande maioria foi e continua sendo proveniente do Haiti. As contratações eram irregulares até 1919 e por esse motivo não há números confiáveis acerca da presença haitiana no país nesse período. A partir dessa data, o governo militar de ocupação estadunidense ${ }^{4}$ formalizou um sistema de contratos regulados para a importação desses trabalhadores que passaram a ser cerca de 5.000 anualmente. Os censos dominicanos registraram 28.258 haitianos em 1920 e 52.657 em 1935 (WOODING; MOSELEYWILIAMS, 2004).

Por décadas os braceros, contratados no campo haitiano formaram a base do trabalho que sustentou a produção açucareira da República Dominicana. Passaram a residir nas proximidades das áreas canavieiras em povoações conhecidas como bateyes - inicialmente alojamentos para trabalhadores, transformados depois em bairros com população predominantemente haitiana ou dominico-haitiana. Nesses locais, há carência de serviços básicos como saúde, educação e saneamento. Configuram-se, ainda hoje, como espaços segregados em várias áreas do país. "Na atualidade há umas 30.000 famílias bateyanas. Todas elas sofrem os resultados da negligência dos proprietários de açúcar, do governo e dos países importadores, como Estados Unidos ou Reino Unido” (REVUELTA, 2017, p. 1, tradução nossa).

A presença crescente de haitianos na República Dominicana provocou o surgimento de reações contrárias, tanto da elite quanto da população pobre. Mais do que xenofobia, a aversão aos haitianos ficou conhecida como anti-haitianismo, marcada profundamente pelo preconceito racial. Entre os dominicanos, é comum a associação dos haitianos e descendentes com o estrito trabalho nos canaviais. Por esse motivo, grande parte da população nega a ancestralidade africana para não se assemelhar aos haitianos. De acordo com Grondin (1985),

\footnotetext{
${ }^{4}$ Os Estados Unidos, que já haviam ocupado militarmente o Haiti em 1915, iniciaram uma ocupação na República Dominicana em 1916 e permaneceram até 1924.
} 
no imaginário de grande parte da população, ser negro significa ser haitiano e, portanto, cortador de cana. Uma manifestação da colonialidade do pensamento sob a forma de racismo.

Durante toda a história da migração haitiana nesse país, os migrantes conviveram com o desrespeito verbal, a segregação residencial, a ausência de serviços essenciais, deportações arbitrárias, as piores remunerações e os trabalhos mais precários. Enfim, uma série de abusos e violações que foram amplamente denunciadas internacionalmente por organizações de Direitos Humanos. O ápice da violência aconteceu em 1937, quando o ditador Rafael Leonidas Trujilo, que governou o país entre 1930 e 1961, ordenou a matança de milhares de haitianos, principalmente nas áreas fronteiriças. Não se sabe o número de mortes, mas as estimativas chegam a 30.000 (WOODING; MOSELEY-WILIAMS, 2004).

Apesar da continuidade das contratações temporárias, a República Dominicana passou a ser um destino, ao menos provisório, da diáspora haitiana. Os 275 quilômetros de fronteira entre os dois países e a rede de estradas que os conectam apresentam menos obstáculos à entrada do que outros vizinhos do Caribe, por exemplo. Desse modo, essa migração aumentou durante o século XX e o Censo de Imigrantes Haitianos realizado pela Oficina Nacional de Estatística, em 1991, registrou a presença de 245.000 deles no país (WOODING; MOSELEY-WILIAMS, 2004).

Soma-se ainda a grande quantidade de domínico-haitianos, que são os filhos e netos nascidos na República Dominicana, estimados em 260.000 na década de 1990 (WOODING; MOSELEY-WILIAMS, 2004). Por esse motivo, frequentemente, estima-se em mais de 500.000 o número de haitianos e descendentes residentes no país. Entretanto, esses autores fazem a ressalva das inúmeras deportações, muitas delas coletivas, fazendo com que os números apresentados possam ser superestimados. Os números inflados também são utilizados no discurso político contrário à essa migração, quando se argumenta que o Estado dominicano tem arcado com os custos sociais da presença haitiana dentro de suas fronteiras.

De todo modo, a República Dominicana é um dos mais destacados destinos da migração haitiana. Apenas os Estados Unidos têm uma população de migrantes haitianos comparável em números, afirma Martínez (2011). Obviamente, a menor distância e os menores custos da migração para o país vizinho ajudam a entender a permanência desse 
fluxo. Apesar de ser o mais “acessível” é o menos desejado dos destinos e muitos dos que lá estão, almejam migrar para outros países que ofereçam melhores condições de vida.

\begin{abstract}
Paradoxalmente, os haitianos consideram a República Dominicana como o menos desejado dos destinos internacionais da migração. Em outro lugar, observei que a maioria dos conhecimentos dos haitianos sobre seu vizinho na ilha de Hispaniola parece estender-se pouco além da sua reputação como um mundo de plantação que absorve o mais despreparado dos emigrantes do país. Os residentes das zonas rurais fronteiriças do sudeste do Haiti, as principais áreas de onde partem os migrantes, conhecem o país vizinho melhor, mas mantêm poucas opiniões melhores sobre isso. No Sudeste, onde fiz meses de campo etnográfico, rumores e lendas descrevem a República Dominicana como um lugar de intriga, traição, magia, loucura e assassinato (...) A República Dominicana não é, enfaticamente, um lugar onde a maioria dos haitianos desejaria se instalar, ao menos no momento em que saem de casa pela primeira vez (MARTÍNEZ, 2011, p. 51, tradução nossa).
\end{abstract}

Além das violações mencionadas, em 2004, a Ley General de Migración aplicou uma exceção ao princípio do jus soli que permite negar a cidadania dominicana aos filhos de pessoal diplomático, dos migrantes não documentados e trabalhadores temporários, considerando-se que todos esses são migrantes em trânsito. A partir desse momento, muitos haitianos foram deportados e milhares de crianças nascidas em solo dominicano tornaram-se apátridas (BERNARDES, 2016). Isso porque, para as autoridades dominicanas, grande parte da população haitiana no país encontra-se em trânsito e não reside definitivamente.

Em setembro de 2013, o Tribunal Constitucional da República Dominicana emitiu a sentença 168-13 que causaria ainda maior impacto na vida dos haitianos e dominicanos de ascendência haitiana residentes no país. A decisão passou a considerar que todos os nascimentos de filhos de imigrantes em situação irregular no país, desde 21 de junho de $1929^{5}$, se enquadrariam na definição de "pessoas em "trânsito". Diante de tantos abusos, inclusive respaldados em lei, não é difícil imaginar o porquê de muitos haitianos não terem a República Dominicana como destino permanente e sim, como uma etapa provisória em seus projetos migratórios.

\footnotetext{
${ }^{5}$ Data da Constituição Dominicana de 1929, na qual filhos de estrangeiros em trânsito não mais teriam direito à nacionalidade dominicana.
}

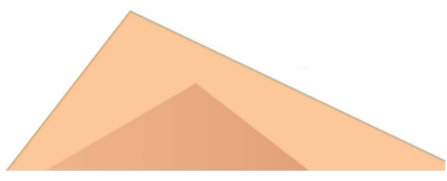


Outro destino da migração haitiana é o arquipélago das Bahamas. Essa migração começou na década de 1950, quando o crescimento do turismo e a instalação de empresas offshore demandou a contratação de trabalhadores migrantes dos Estados Unidos, mas também do Caribe. Alfonso (2012) afirma que, nesse período, a migração era predominantemente temporária. Os haitianos passavam temporadas, juntavam dinheiro e retornavam ao Haiti. Nas décadas seguintes, com a consolidação do país como destino turístico e com o processo de transição para a independência - que ocorreu em 1973, os haitianos passaram a migrar por conta própria e serem empregados no setor hoteleiro, na construção civil e na agricultura.

À medida que foi se configurando uma comunidade haitiana no sul da Flórida, as Bahamas se converteram em lugar de passagem para Miami. Transformou-se em um destino intermediário, onde os migrantes de outras partes do Caribe permaneciam um tempo necessário para organizar a continuidade da viagem. Também em muitos casos, migrantes pagavam passagens de barco até a Flórida, mas eram abandonados ali. Ainda que muitos haitianos migrem para as Bahamas, o fazem tentando chegar aos Estados Unidos, mas a espera no lugar de passagem pode durar anos ou até mesmo a vida inteira. "Isto marca a migração haitiana nestas ilhas com um selo particular de não pertencimento" (ALFONSO, 2012, p. 23, tradução nossa).

Paradoxalmente, a regularização do status nas Bahamas através da aquisição de uma autorização de trabalho ou residência promove a migração para o sul da Flórida. As autorizações de trabalho e residência permitem que os migrantes encontrem empregos com melhor remuneração, o que lhes permite economizar dinheiro para futuras migrações e solicitar um visto para entrar nos Estados Unidos. Além disso, os cidadãos das Bahamas com passaportes válidos não precisam de visto para entrar nos Estados Unidos (JACQUES, 2011, p. 93, tradução nossa).

Essa característica enquanto local de passagem teve consequências diretas no sistema migratório bahamês que impôs uma série de restrições para a regularização como residente. Dentre elas, entrada no país antes de 12 de janeiro de 1985, não possuir antecedentes criminais e estar trabalhando. Os poucos que conseguem atingir esses critérios, amargam anos para finalizar o processo, exceto se possuem investimentos no país (JACQUES, 2011).

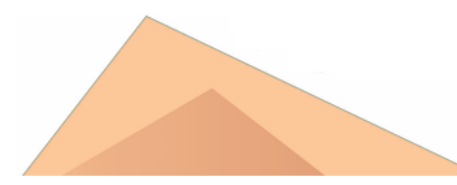


Mesmo com as restrições, a migração haitiana teve continuidade no início dos anos 1990, período de grande instabilidade política no Haiti e voltou a crescer após a catástrofe de 2010. De acordo com Alfonso (2012), o Censo de 2001 contabilizou 21.426 haitianos no país, o que representava $7 \%$ da população. Porém, o mesmo autor sugere que aproximadamente 60.000 vivam no arquipélago, já que cerca de dois terços são indocumentados.

Assim como na República Dominicana, os haitianos estão sujeitos à discriminação racial generalizada. São acusados de inflarem os serviços de saúde e educação e, como correm o risco de deportação, vivem uma grande segregação residencial em favelas com ausência de serviços básicos. "O trabalho manual que os haitianos desempenham na agricultura, paisagismo, construção, hotéis e restaurantes é comumente referido como "trabalho haitiano"” (JACQUES, 2011, p. 98, tradução nossa). Isso talvez indique que o haitiano ocupa o lugar do "outro", do não estabelecido, na sociedade nacional.

A localização das Bahamas no Caribe contribuiu para a configuração enquanto local de passagem da migração haitiana, isto é, um destino temporário que serve para conectar o noroeste do Haiti e o sul da Flórida (JACQUES, 2011). Contudo, Alfonso (2012) acrescenta que a posição ocupada por esse país no cenário geopolítico regional reflete diretamente nas práticas transnacionais desses migrantes. Ele sugere que os haitianos que para lá se destinam não são tão pobres a ponto de permanecerem no Haiti ou migrarem para a República Dominicana, mas também não têm recursos suficientes para chegarem diretamente aos Estados Unidos ou Canadá.

Isso significa que o espaço intermediário das Bahamas, entre centro e periferia, também é refletido na condição social dos migrantes que conectam o Haiti aos Estados Unidos através de suas práticas transnacionais. Há desde uma minoria que se estabeleceu no país e atualmente consegue acessar tanto os Estados Unidos quanto o Haiti, fazendo viagens ou remessas, até aqueles que se restringem a contatos esporádicos com parentes nos dois lugares. A posição que cada um ocupa nas Bahamas reflete o grau e o tipo de interação com familiares que estão fora. 
Na última década, o debate em torno na migração haitiana nas Bahamas voltou a se acirrar. A nova política migratória das Bahamas, em vigor desde 1 de novembro de 2014, exige que todos tenham um passaporte ou documento bahamês. Sem passaporte ou autorização de trabalho, migrantes são sumariamente detidos e, em alguns casos, deportados. Embora essa lei sirva para os migrantes em geral, é principalmente sobre os haitianos que seu peso recai, pois são os mais excluídos da restrita política de regularização. Nos últimos anos, aumentaram as vistorias policiais e detenções nas favelas de Nassau, capital do país, onde vivem a maioria dos haitianos (ROBLES, 2015).

Com os pais em situação indocumentada, as crianças não podem obter passaporte no país e caso solicitem no Haiti, perdem a futura possibilidade de cidadania bahamense ao completar 18 anos. Com isso, muitas crianças estão sendo impedidas de estudar por não portarem documentos nem do Haiti nem das Bahamas. Essas medidas trazem sérias consequências para a segunda e terceira gerações, pois aqueles que conseguirem permanecer no país, dificilmente terão acesso à educação e, provavelmente, continuarão exercendo os mais precários e mal pagos serviços.

Como afirmamos, a migração para as Bahamas a partir da década de 1960 esteve associada ao trânsito de migrantes para a Flórida. De acordo com Joseph (2015), ainda na década de 1950, a elite haitiana enviava seus filhos para estudarem nos Estados Unidos. Porém, foi durante o período da ditadura Duvalier que esse fluxo se intensificou. Nesse período, a migração era predominantemente de intelectuais e membros de diversas categorias da classe média.

Para Audebert (2012), essa migração deve ser analisada no contexto da aproximação dos Estados Unidos com o Haiti, principalmente após a ocupação militar. A presença estadunidense exerceu influência também no plano cultural. O ensino de inglês tornou-se obrigatório durante o governo de Élie Lescot (1941-1946) e aumentou o número de igrejas protestantes americanas no país. Durante o século XX, o expansionismo e intervencionismo americano no Caribe aumentou a dependência política e econômica do Haiti em relação a eles. "Foi dentro do quadro dessa nova forma de dependência que a emigração para países

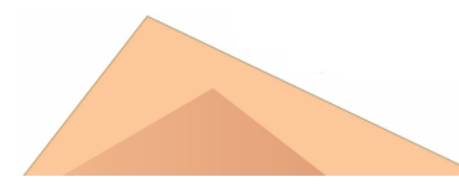


vizinhos foi desenvolvida e depois para os próprios Estados Unidos” (AUDEBERT, 2012, p. 24, tradução nossa).

No contexto ditatorial, os primeiros perseguidos a deixarem o país foram os membros da elite mulata que migraram para os Estados Unidos ainda no final da década de 1950. A autoproclamação de François Duvalier como presidente vitalício, em 1964, assustou profissionais da classe média que também se exilaram. Médicos, professores, advogados e outros profissionais liberais passaram a migrar com suas famílias para os Estados Unidos. Nas décadas de 1970 e 1980, apesar de algumas medidas liberalizantes na política e na economia, a pobreza generalizada, principalmente no campo, impulsionou milhares de camponeses pobres à migração. Desse modo, o que era restrito a um pequeno grupo nos anos iniciais da ditadura, generalizou-se no universo haitiano nos anos finais e mesmo após o duvalierismo.

De acordo com Audebert (2012), no período de 1956 a 1986, 154.108 haitianos migraram legalmente para os Estados Unidos. Entretanto, a grande maioria encontra-se fora desse número pois a prática comum era solicitar o visto de turista, quando não era possível obter o de residente, e prolongar a estadia de maneira irregular. Além disso, muitos partiam sem qualquer documentação, através das frágeis embarcações pelo mar do Caribe. Entre 1977 e 1981, mais de 50.000 haitianos chegaram vivos à costa da Flórida (STEPICK, 1992). Porém, é sobretudo no conturbado período pós Duvalier, no final dos anos 1980, que o fenômeno dos boat people ganha destaque ${ }^{6}$.

A migração haitiana para os Estados Unidos intensifica-se no contexto do golpe de Estado implementado pelo General Raoul Cédras que depôs o presidente Jean-Bertrand Aristide, em 1991. De acordo com Audebert (2012, p. 35, tradução nossa), "durante os três anos do golpe, entre 3 mil e 5 mil partidários de Aristide foram assassinados. Essa situação serviu de catalisador para o relançamento de fluxos migratórios para a Flórida". Nos anos 2000, o sentimento de insegurança, a instabilidade política e a precariedade das condições de

\footnotetext{
${ }^{6}$ Nesse período, foi grande a reação contrária dos americanos em relação aos haitianos. Discursos racistas que associavam os haitianos à AIDS e à criminalidade eram frequentes.
}

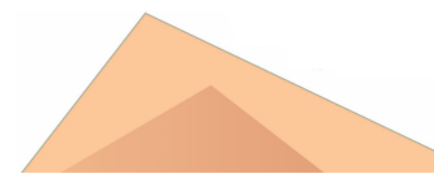


vida vão continuar apontando a migração como uma saída para grande parte da população, sobretudo os mais jovens.

Alguns autores como Télémaque (2012), Nieto (2014) e Baptiste e Vieira (2016) indicam que o número de haitianos residentes nos Estados Unidos atualmente é de cerca de 1 milhão, distribuídos em diversos estados, mas com grande concentração na Flórida $(46,2 \%)$, Nova York (25,1\%), Massachusetts $(8,2 \%)$ e New Jersey $(7,4 \%)$ (MENINO, 2009). Em alguns desses locais, as comunidades haitianas adquiriram grande organização política e um avançado debate acerca dos direitos dos migrantes. "Como resultado, dois deputados estaduais de ascendência haitiana já foram eleitos na legislatura de Massachusetts desde 2000, e mais haitianos estão buscando ativamente cargos eletivos em vários outros estados” (TÉLÉMAQUE, 2012, p. 27).

O primeiro destino de uma migração massiva de haitianos nos Estados Unidos foi Nova York. Como mencionamos, em fins da década de 1950, esses migrantes eram principalmente políticos e membros de diversas categorias da classe média. Por terem ocupado postos privilegiados na sociedade haitiana e, de modo geral, usufruído de boa formação, esses migrantes se estabeleceram na área metropolitana de Nova York, mas evitavam a associação com uma "comunidade haitiana" fora do Haiti. Glick-Schiller et al (1987) mostraram que as primeiras associações de haitianos na cidade estavam restritas a clubes recreativos e não buscavam falar em nome de todos os haitianos, e sim reforçar a distinção de classe que trouxeram do país de origem. "Os membros estavam orientados a retornar ao Haiti onde esperavam derrubar o regime de Duvalier e restaurar suas próprias posições políticas e sociais de classe alta” (GLICK-SCHILLER et al, 1987, p. 170, tradução nossa).

Com a mudança no perfil dos migrantes haitianos nos Estados Unidos, que passou a receber cada vez mais uma população pobre, principalmente do Norte e Noroeste do Haiti, as associações se multiplicaram e diversificaram, incorporando o debate étnico e nacionalista. Na década de 1970, com a continuidade da ditadura, aqueles que não tinham meios suficientes para a migração documentada passaram a realizar a viagem para a Flórida através de barcos, no fenômeno conhecido como boat people. É a partir desse momento que 
o número de haitianos em Miami começa a crescer e supera essa população residente em Nova York. Em 2008, estimava-se que entre 350.000 e 400.000 haitianos residiam no estado americano da Flórida (FAGEM et al, 2009).

Os primeiros boat people chegaram à costa da Flórida em 1972 e o fluxo tornou-se regular a partir de 1973, trazendo cada vez mais haitianos que fugiam da precariedade econômica e da insegurança presente no regime de Jean-Claude Duvalier. Também neste ano as Bahamas tornaram-se independentes e dificultaram a entrada e permanência de haitianos no arquipélago, o que fez com que, entre o retorno e uma nova migração, os haitianos optassem pela segunda opção, na maioria dos casos. Desse modo, a Flórida foi se tornando um destino para milhares de famílias haitianas somando-se ao grande de número de hispânicos e caribenhos de outros países que para lá se dirigiam.

Ao analisar essa migração, Audebert (2004) afirma que as frequentes trocas de informações, recursos e produtos, bem como a própria circulação das pessoas entre a Flórida e o Haiti, gerou uma família transnacional haitiana, estruturada por relações fortes entre seus membros. Esse quadro familiar foi fundamental para a continuidade da migração e para a inserção urbana. Fatores como pobreza e o tamanho das famílias dificultaram a migração de todos de uma só vez e assim os jovens, preferencialmente homens, migravam primeiro para depois acolher os demais membros, em uma estrutura de rede migratória.

As decisões (individuais ou não) de migração são articuladas nas redes sociais cuja família é o quadro principal. O enorme afluxo de haitianos para a Flórida por quase 30 anos criou centenas de milhares de famílias transnacionais com grandes fluxos de capital e informações (AUDEBERT, 2004, p. 5, tradução nossa).

A reforma da lei de migração de 1965 aboliu as cotas por nacionalidade e enfatizou a importância da reunião familiar, concedendo $74 \%$ dos vistos de residência nessa categoria até 1980. Isso contribuiu para que muitas famílias haitianas se reunificassem na Flórida, sobretudo em Miami. “Assim, entre 1982 e 2001, 96\% dos 114.400 haitianos admitidos, foram beneficiados pelo reagrupamento familiar" (AUDEBERT, 2004, p. 5, tradução nossa).

Soma-se a isso os reagrupamentos indocumentados, já que no Haiti, frequentemente, a concepção de família extrapola o núcleo de pais e filhos e incorpora primos, tios, avós e até 
vizinhos e amigos de infância. Essa família "alargada" desempenhou importante papel nas remessas de dinheiro e na divisão dos custos no destino. Contrariando as normas de habitação da época, as casas planejadas para cinco ou seis pessoas, agrupavam doze e até quinze membros dessa família haitiana ampliada no auge do reagrupamento, no início da década de 1980. Ao dividir ao máximo o aluguel, podiam economizar preparando-se para uma situação de desemprego ou para a mobilidade residencial futura, desmembrando a família e mudandose para áreas mais periféricas. Em consequência, a forte concentração da população haitiana na área de Miami conhecida como "Little Haiti”, nas décadas de 1970 e 1980, deu lugar a uma dispersão maior em vários bairros periféricos (AUDEBERT, 2004).

Nas décadas iniciais do século XXI esse fluxo da migração haitiana diminuiu, devido às maiores restrições e ao controle das fronteiras estadunidenses. Porém, a intensa circulação de informações, capitais e mercadorias entre a Flórida e o Haiti mantém o papel de destaque de uma rede transnacional, tendo as famílias como nós centrais.

A terceira maior comunidade de haitianos nos Estados Unidos está em Boston, no estado de Massachusetts, com números que se aproximam das 100.000 pessoas (FAGEM et al, 2009). Embora o censo de 2004 tenha contabilizado 60.630 nacionais do Haiti residindo na cidade, Jackson (2011) alerta para o fato de que muitos haitianos chegaram por meio da migração interna, tendo residido antes em outras cidades americanas, além dos casos daqueles que chegaram com visto de turista e permaneceram sem regularizar a situação no país.

Assim como em Nova York, as chegadas começaram no fim da década de 1950 tendo as mesmas características: comerciantes, profissionais liberais, estudantes e outros, em geral com recursos e boa formação educacional que fugiam da ditadura. Mais pobres e menos escolarizados, aqueles que chegaram no fim da década de 1980 e durante os anos 1990 partiram de diversas regiões do Haiti, grande parte de origem rural com prolongada exposição à violência. Diferente dos anteriores, tinham pouca ou nenhuma experiência com migração (JACKSON, 2011). Alguns se beneficiaram dos processos de reunião familiar e outros das solicitações de refúgio no contexto do golpe de Estado de 1991 e a violência agravada nos anos seguintes.

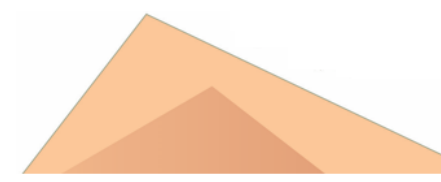


O estudo de Jackson (2011) mostra que a concepção de diáspora foi sendo concebida pelos haitianos em Boston ao longo de várias décadas. Enquanto os primeiros vivenciaram pouca interação na sociedade de destino e investiam mais no Haiti do que em Boston, os últimos viram na interação comunitária, baseada nos laços de conterraneidade, uma convergência da consciência diaspórica.

Essa mudança nos usos do conceito pelos haitianos reflete os distintos contextos migratórios entre as décadas de 1950 e 2000. Apesar da situação política do Haiti, os primeiros viam na migração a possibilidade de acesso à educação e ao trabalho, mas em grande parte vinculado ao desejo de retorno. Já os que migraram nas últimas décadas deram um sentido político à diáspora e contribuíram mais intensamente para que Boston fosse vista não apenas como um lugar para ganhar dinheiro, mas também como o centro da atividade política e cultural da diáspora.

A diáspora haitiana nos Estados Unidos tem se mostrado bastante ativa na vida política e cultural nos lugares onde estão inseridos. Além dos casos acima elencados, há contingentes significativos desses migrantes nos estados de Nova Jersey, Pensilvânia, Geórgia e Connecticut (MENINO, 2009). Nas últimas duas décadas surgiram dezenas de programas de rádio e televisão que se destinam a produzir conteúdo para essas comunidades. Até mesmo onde os haitianos estão em pequena quantidade, como no estado de Michigan, as associações têm se configurado como elementos importantes da diáspora (VERNA, 2011). Se entre os anos de 1970 e 1980, quando a migração indocumentada era expressiva, esconderse era uma estratégia vital para evitar a deportação, a partir dos anos 1990 observou-se uma consolidação da diáspora com maior engajamento político em diversas esferas.

No Canadá, os haitianos começaram a se estabelecer no mesmo período da migração para Nova York, tendo também a ascensão de Duvalier como causa principal dessa mobilidade inicial. Assim como em outros destinos, políticos e profissionais liberais iniciaram esse processo que foi alterando-se nas décadas posteriores no que diz respeito à sua composição demográfica e social. Todavia, a relação dessa comunidade com o governo canadense foi significativamente diferente. 
De acordo com Fagem et al (2009) o início da migração haitiana para o Canadá coincidiu com a passagem do poder político da província do Québec das mãos dos conservadores anglófonos para os liberais francófonos, em 1960. Para fortalecer essa base, precisavam de profissionais de língua francesa que contribuíssem com as transformações que desejavam. Assim, o Québec, e mais precisamente a cidade de Montreal, tornou-se o grande centro da diáspora haitiana no país.

Como os haitianos se assentaram no Québec e se concentraram em Montreal, a comunidade é percebida como um número maior do que realmente é. Em 2006, havia 102.061 cidadãos de origem haitiana no Canadá, um aumento de 20.000 desde 2001, com 91.435 residentes no Quebec. É a segunda maior população de origem caribenha no Canadá, mas apenas metade da população jamaicana (FAGEM et al, 2009, p. 32, tradução nossa).

Médicos, enfermeiras, professores e agrônomos ajudaram a ampliar a oferta e a qualidade dos serviços sociais na província. Nos anos 1960 se podia contar mais de duzentos médicos e cerca de mil professores haitianos no Quebec (ICART, 2004). O elevado grau de instrução desses profissionais contribuiu para atenuar o preconceito racial. Situação diferente será vivenciada pelos haitianos migrantes a partir de meados da década de 1970.

Essa migração aumentou bastante a partir de 1975, como resultado da reunificação familiar e dos pedidos de refúgio. Desse modo, a composição da migração mudou e começaram a chegar haitianos de diferentes estratos sociais. É nesse contexto que as relações entre haitianos e canadenses passam a ser mais conflituosas. Dorino (2009) argumenta que a crescente presença de haitianos que falavam apenas o creóle, a recessão econômica dos anos 1980 e a existência de trabalhadores qualificados em número suficiente, contribuíram para a rejeição cada vez maior desses migrantes.

Embora o idioma tenha sido um fator fundamental na integração dos haitianos no Québec, a racialização dessa migração dificultou a mobilidade social de muitos deles. Em 2005, a taxa de desemprego entre os jovens haitianos era quase duas vezes maior do que a média da província. 15,9\% contra 8,2\% (NIETO, 2014). Agrava o fato de a comunidade de origem haitiana no Québec ser predominantemente jovem, a maioria da segunda ou terceira

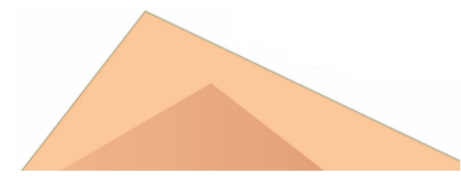


gerações. Segundo Boucard (2006), em 2001, mais de 50\% dessa população tinha menos de 30 anos de idade.

O idioma francês também foi um fator que contribuiu para que milhares de haitianos se deslocassem para os territórios franceses ultramarinos de Guadalupe, Martinica, St. Martin e Guiana Francesa. Nesses locais, a população haitiana corresponde de 30 a $50 \%$ da população migrante (LAETHIER, 2015) e desde a década de 1960 tem marcado profundamente as relações com a população local e outros grupos de migrantes, pois, por se tratar de um grupo numeroso, manteve visibilidade e provocou rejeições.

De acordo com Alfonso (2012), as estimativas indicam que em Guadalupe vivem entre 15.000 e 20.000 haitianos; 15.000 em St. Martin; menos de 10.000 em Martinica e cerca de 40.000 na Guiana Francesa. Todavia, o mesmo autor alerta para a oscilação desses números, tendo em vista que muitos haitianos estão em deslocamento, podendo permanecer um tempo variável até acessar outro destino. Acrescentamos o fato de que a recente mobilidade a partir de 2010 pode ter incorporado ainda mais migrantes a esses destinos, como foi o caso da Guiana Francesa.

Diferente do que aconteceu na América do Norte, a migração haitiana para os territórios franceses do Caribe iniciou com uma mobilidade da força de trabalho nos anos iniciais da década de 1960. Trabalhando em diversas áreas, principalmente na agricultura e construção civil, esses migrantes foram fundamentais, já que, naquela época, esses territórios eram pouco povoados a ponto de produzir e contribuir com a economia francesa. Para se ter uma ideia, na Guiana Francesa, a população estrangeira correspondia a 1/10 em 1946 e saltou para 1/3 em 1990. Surinameses, brasileiros e principalmente haitianos estiveram na base do crescimento populacional do local (CALMONT, 1993).

Iniciada em 1963, a migração de haitianos foi aumentando até a média de entrada anual chegar a 2.000 pessoas entre os anos de 1980 e 1984 (CALMONT, 1993). Nesse período, o visto de permanência na Guiana Francesa já estava condicionado à comprovação de um vínculo empregatício com carteira assinada. Essa restrição fez surgir uma nova rota através do Suriname que se configurou como um espaço de passagem para a maioria dos

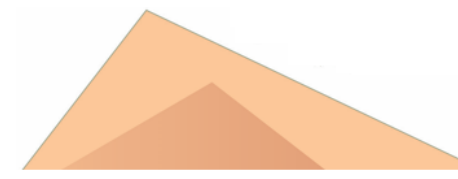


haitianos. Munidos de um visto surinamês temporário, os haitianos deslocavam-se para a Guiana Francesa, principalmente para as cidades de Saint-Laurent-du-Marroni e Cayenne.

Apesar da emergência do Suriname enquanto espaço de passagem, Joseph (2015) relata que os primeiros haitianos a chegarem no país foram recrutados no Haiti para trabalharem nas plantações de cana-de-açúcar em 1977, criando as bases de migrações futuras. Outros passaram a utilizar este país com um local de estadia temporária, uma pausa necessária no movimento em direção ao vizinho departamento francês. Diante das dificuldades em conseguir a documentação para residir na Guiana Francesa, muitos se estabeleceram em Paramaribo e criaram bases de redes migratórias que foram sustentadas ao longo de décadas.

A nova "rota do Suriname" é seguida por aqueles que não podem obter um passaporte, um visto ou qualquer outro documento, por exemplo, um convite escrito de um parente que já tenha residido legalmente na Guiana Francesa. Eles então recorrem a redes de migração, também chamadas de "vein" em créole. É claro que há outro acesso mais legal para a entrada na Guiana Francesa: o migrante pode comprar um visto de curto prazo que menciona "os Departamentos Franceses das Américas" e, em seguida, simplesmente permanecer. Mas o custo é muito alto. Uma alternativa mais barata é a "rota do Suriname" com o rakètè, os contrabandistas. Esses contrabandistas trabalham com "agências" (ajans), redes de intermediários que são distribuídos ao longo da rota (LAETHIER, 2015, p. 233, tradução nossa).

É necessário apontar que os destinos adquirem significados variados na migração haitiana e que, às vezes, o projeto migratório realiza-se em etapas. Entrar na Guiana Francesa e regularizar-se legalmente é um importante passo para se chegar à França. "Aqueles que chegam ou já estão na Guiana Francesa consideram este país como 'país de França', o que dá outro significado à sua mobilidade" (LAETHIER, 2015, p. 14).

No cenário das discussões da Diretiva do Retorno ${ }^{7}$ na Comunidade Europeia, em 2009, o governo francês solicitou do governo do Suriname diminuição dos vistos para haitianos com o objetivo de controlar a entrada destes na Guiana Francesa. Desse modo, como estratégia de contornamento, outras rotas e redes começaram a surgir. É nesse contexto

\footnotetext{
${ }^{7}$ Diretiva 2008/115/CE do Parlamento Europeu que passou a vigorar em 2010. Estabeleceu procedimentos comuns aos países membros da U.E. no que diz respeito aos migrantes em situação irregular, prevendo deportação e em alguns casos prisões sem julgamentos.
}

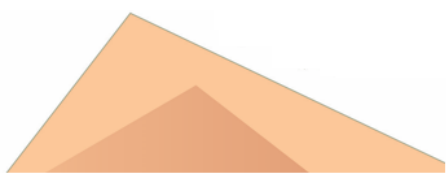


que se insere a entrada de haitianos por Tabatinga, Amazonas, a partir dos primeiros meses de 2010.

Com a restrição do Suriname, para alcançar a Guiana Francesa, a maioria dos haitianos que entravam por Tabatinga seguiam uma rota de vários dias cujos pontos principais eram Manaus, Santarém, Macapá e Oiapoque. Ao chegar na cidade fronteiriça de St. Georges, procuravam a polícia para adquirir um visto temporário com o qual se deslocavam para Cayenne e, por fim, pediam refúgio na prefeitura (JOSEPH, 2015). Porém, em 2011, o governo francês deixou de conceder esse visto e muitos migrantes passaram a fazer o trajeto Oiapoque-Cayenne de balsa, em precárias condições de segurança. Apesar das restrições e da vigilância, essa rota ainda funciona como via de acesso para migrantes, principalmente haitianos e brasileiros. ${ }^{8}$

Outros países e ilhas do Caribe também se inserem na diáspora haitiana, com populações de migrantes numericamente menores, mas igualmente relevantes para pensar os processos que dão forma ao que estamos tratando aqui como espaço transnacional haitiano, notadamente a partir da articulação desses destinos com o Haiti, mas também com outros locais. É assim, por exemplo, com os cerca de 10 mil haitianos que vivem nas Ilhas Turks e Caicos, possessão inglesa que incorporou o trabalho de haitianos na expansão do turismo na década de 1990 (ALFONSO, 2012).

Apesar da residência de algumas centenas e até milhares de haitianos, alguns locais estão bastante associados ao espaço de trânsito, principalmente para os Estados Unidos. São os casos de Porto Rico e Jamaica que, devido à proximidade, serviram de pontos estratégicos em momentos de grande tensão no Haiti (ALFONSO, 2012). Mais recentemente, a Venezuela se inseriu nas rotas dos haitianos para chegarem até o Brasil, embora, segundo Machado (2010), os censos venezuelanos registraram um fluxo pequeno, porém permanente, desde a década de 1950, chegando no início dos anos 2000 com uma população oficializada de cerca de 1.661 haitianos no país.

\footnotetext{
8 "Naufrágio com imigrantes revela faceta do tráfico". Disponível em: http://selesnafes.com/2017/02/naufragio-comimigrantes-revela-faceta-do-trafico/
} 
Outro tradicional destino dessa migração, a França, abriga atualmente entre 25.000 e 30.000 haitianos que se concentram, predominantemente, nos subúrbios de Paris (MOONEY, 2011). Devido à relação colonial, há séculos ocorrem movimentações de pessoas entre os dois países, mas até a década de 1970, o número era bastante limitado e estava restrito a estudantes e professores que dispunham de meios para acessar um destino tão distante.

Esses migrantes, em geral de classe média alta e alta, vinham principalmente de Porto Príncipe e não viam a França como um novo país, mas pretendiam voltar sob um sistema mais democrático (MOONEY, 2011, p. 118, tradução nossa).

O pioneiro estudo de Bastide, Morin e Raveau (1974) apontou 400 haitianos na França em 1970, sendo 300 estudantes. Dez anos antes, eram apenas 100. De modo semelhante ao que ocorreu em outros países, o contexto ditatorial exerceu influência direta sobre a diversificação da migração no que se refere aos destinos e ao perfil dos migrantes. Dos anos 1980 até a atualidade, há um fluxo com maior heterogeneidade social e etária. É justamente nessa década que o número de migrantes haitianos na França mais cresceu, passando de 4.724 em 1982 para 12.311 em 1990 (MOONEY, 2011).

Segundo Primé (2013), enquanto os primeiros facilmente se integraram na sociedade local, em grande parte devido ao elevado grau de educação formal, os demais encontraram dificuldades. Como muitos chegaram com visto de turista e permaneceram, a ausência de documentação legalizada desdobrava-se na inacessibilidade de emprego e outros serviços. Mooney (2011) afirma que a laicidade do Estado francês afastou instituições religiosas que em outros locais atuavam como mediadores, priorizando a relação do indivíduo com as instituições estatais. Isso enfraqueceu importantes fontes de apoio para os migrantes haitianos, como aconteceu nos Estados Unidos.

A continuidade desse fluxo esteve sustentada basicamente nas redes familiares. Porém, em momentos de crise política no Haiti, algumas entradas foram realizadas por meio de asilo político e refúgio. Com o golpe de 1991, estudantes e intelectuais apoiadores de Aristide buscaram apoio nas embaixadas e alguns conseguiram chegar à França. Entre 2003

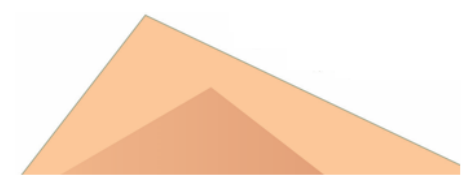


e 2004 a situação se repete. Mais uma vez, após o terremoto de 2010, o governo francês concedeu 700 bolsas para estudantes haitianos em universidades francesas (PRIMÉ, 2013).

Contudo, segundo Mooney (2011), o nacionalismo francês opera como um importante fator de segregação. Por exemplo, em 2002, a taxa de desemprego entre os haitianos era de 28,4\% contra 12,5\% dos franceses. Embora o grau de escolaridade, habilidades em língua francesa e experiência profissional provavelmente influenciem nas altas taxas de desemprego entre os haitianos, as dificuldades em obter cidadania francesa e discriminações diversas também contribuem.

Essa diversificação dos destinos da migração haitiana se reflete nos aportes financeiros. Uma das consequências diretas da migração haitiana é o envio de remessas. O envio de dinheiro aos familiares está intimamente ligado ao projeto migratório posto em prática por milhões de haitianos pelo mundo. Tal é a importância disso que entre 2005 e 2014, as remessas de migrantes representaram entre 20 e $30 \%$ do PIB haitiano (MAGAlHÃES; BAENINGER, 2016). De acordo com Mooney (2011), durante os anos 2000, as transferências representaram entre 3 e 4 vezes o valor das exportações do Haiti e correspondeu ao dobro do orçamento anual naquela década. A cada ano, entre 1,5 e 1,8 bilhão de dólares era transferido para o Haiti através de seus migrantes. Para além desses números estão as transferências informais, transportadas pelos próprios migrantes.

Charry (2017), ao analisar os números das transferências de migrantes para os países da América Latina, informa que o Haiti recebeu 2,4 bilhões de dólares provenientes dessa fonte em 2016. A autora destaca ainda que nos países centro-americanos e caribenhos esses recursos têm maior impacto.

Nos países centro-americanos e do Caribe se evidencia igualmente uma alta das remessas impulsionadas pela recuperação do emprego estadunidense. Se bem que nestas nações ingressam muito menos recursos que no México, nelas as remessas são mais importantes para suas respectivas economias. Enquanto no México as remessas equivalem a 2,5\% do Produto Interno Bruto, no Haiti são 29,6\%; em Honduras, $18,4 \%$ e em El Salvador, 17,2\%. Pelo contrário, na Argentina, Brasil e Chile estes giros implicam um ingresso pequeno, com apenas $0,1 \%$ do seu PIB (CHARRY, 2017, p. 88, tradução nossa). 
Também são diversas as finalidades e os usos dessas transferências. Geralmente, as famílias com mais recursos econômicos, tendem a destinar parte ou todo o dinheiro recebido para a aquisição ou melhoria de bens, como reforma ou compra de imóveis ou automóveis. Já aquelas com menos recursos, tendem a utilizar o dinheiro imediatamente nas despesas de consumo familiar. De acordo com os dados obtidos no Projeto "Estudos sobre a Migração Haitiana ao Brasil e Diálogo Bilateral”, mais de 80\% das remessas são destinadas ao consumo da família (FERNANDES, 2014). Desse modo, parece haver uma relação direta entre essas transferências e dependência econômica. "A forma de utilização das remessas é uma expressão da estratificação socioeconômica no Haiti. É justamente nos domicílios mais pobres onde as remessas serão utilizadas prioritariamente para o consumo" (MAGALHÃES; BAENINGER, 2016, p. 246).

As remessas podem ampliar o nível de consumo da família e estimular novas migrações. Como vimos em vários casos, na migração haitiana, quando alguém se estabelece em algum destino, tende a mobilizar recursos para que um familiar também o faça. Não havendo possibilidades para que isso aconteça, novos destinos podem surgir, fomentando futuras mobilidades. É nesse contexto que milhares de haitianos alcançam diversos países da América do Sul, atualmente. As dificuldades de entrada e de regularização documental nos tradicionais destinos desses migrantes, aliadas às transformações políticas e econômicas na periferia do capitalismo global, fizeram com que países como Equador, Chile, Argentina e Brasil se incorporassem ao espaço transnacional haitiano.

Entretanto, depois de incorporar os países sul-americanos ao espaço transnacional do Haiti, os migrantes haitianos têm abandonado o subcontinente e implementado novas migrações em direção aos Estados Unidos. Contribuem para isso, fatores como a segmentação do mercado de trabalho, baixos salários, aumento dos custos de vida, racismo e uma ilusão generalizada de que o governo de Joe Biden mudará a política migratória estadunidense. Porém, o que se tem observado, é o impedimento massivo e violento posto em prática pelas autoridades migratórias dos Estados Unidos (JESUS, 2019; MIRANDA, 2021). Uma vez mais os haitianos são rechaçados e impedidos de entrar. Entre um país

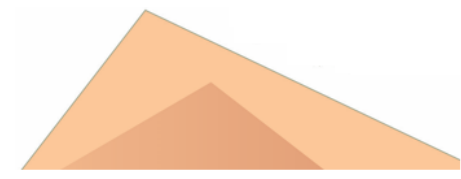


destroçado e as portas fechadas do Norte Global, eles continuam à espera em um intenso e complexo trânsito.

\section{CONCLUSÃO}

O processo colonial, as intervenções internacionais e a instabilidade política e econômica permanentes criaram condições de produção e reprodução da pobreza e apontaram a migração como alternativa de vida para milhões de haitianos, sejam elas migrantes ou não. Mais de um terço da população do Haiti vive fora e faz com que as remessas sejam o principal aporte financeiro do país. Entretanto, ao mesmo tempo em que a diáspora haitiana traz alternativas de vida para milhares de famílias, ela retrata o precário quadro social vigente.

Tais condições, ainda no início do século XX, impulsionaram milhares de haitianos à migração sazonal para o trabalho nos canaviais da República Dominicana e de Cuba. A permanência de alguns grupos nos locais de trabalho originou consideráveis e contínuos fluxos migratórios ao longo de todo o século. O padrão temporário, masculino e documentado foi substituído, gradativamente, por outro marcado pela estadia definitiva, pela presença de famílias e pelo elevado grau de indocumentação. As comunidades de haitianos estabelecidas nesses países, embora volumosas, não simbolizam o sucesso de ser um sujeito diáspora como são considerados aqueles residentes nos países ricos.

Foram particularmente importantes as migrações em períodos de agudização das crises políticas e econômicas. Assim, no contexto da ocupação americana do Haiti (19151934), na ditadura da família Duvalier (1957-1986) e na instabilidade provocada pelo golpe de Estado em 1991, milhares de haitianos se destinaram principalmente aos Estados Unidos, ao Canadá e para a França. A continuidade desses fluxos alterou o padrão inicial, predominantemente de classe média e documentado, para outro mais pauperizado e com permanências não autorizadas. Cidades como Miami, Nova York, Montreal e Paris são, ainda hoje, espaços marcantes dessa diáspora e viram o desenvolvimento das segunda e terceira gerações de migrantes.

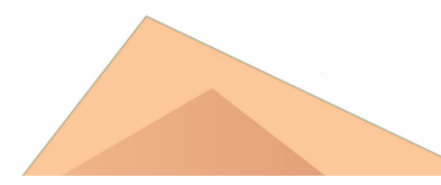


As dificuldades de ingresso nos destinos prioritários da migração haitiana provocaram o surgimento de uma migração por etapas. Alcançar os departamentos ultramarinos franceses da Guiana Francesa, Guadalupe, Martinica e San Martin representava maior possibilidade de chegar à França. Do mesmo modo, residir regularmente nas Bahamas ou em Porto Rico poderia encurtar o caminho em direção aos Estados Unidos. Em muitos casos, a estadia temporária deu lugar à permanência.

Mais recentemente, países da América do Sul que não contavam com grupos significativos de migrantes haitianos passaram a fazer da parte dos destinos dessa população. Embora pequenos grupos já residissem em países como Venezuela, Equador e Brasil, o ano de 2010 marcou o início de uma nova fase da migração haitiana quando o terremoto agravou o precário quadro socioeconômico do Haiti. Entretanto, à catástrofe devem ser somadas outras causas como as dificuldades de acessar os destinos prioritários impostas pelas políticas migratórias restritivas, a presença da Missão das Nações Unidas para a Estabilização do Haiti (MINUSTAH), liderada pelo Brasil, bem como o crescimento da economia brasileira e chilena no início do século XXI.

No novo contexto, as migrações incorporaram variados estratos sociais e não esteve restrito aos sobreviventes do terremoto e sim, envolveu pessoas de todo o Haiti, inclusive residentes em outros países como Equador e principalmente República Dominicana. As dinâmicas recentes da migração haitiana pela América do Sul demonstraram a importância das redes sociais na definição e redefinição dos itinerários assim como nos processos de adaptação e de mudança. Seja nos países do Norte ou do Sul Global, os haitianos seguem apostando na migração como alternativa de vida.

\section{REFERÊNCIAS}

ALFONSO, H. D. La migración haitiana en el Caribe: una proposta para la acción. Servicio Jesuita de Migrantes. Santo Domingo, 2012.

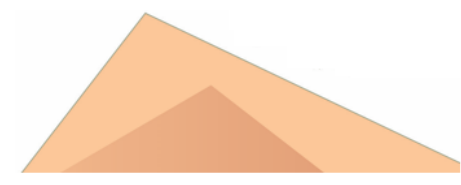


AUDEBERT, C. Immigration et insertion urbaine en Floride: le rôle de la famille transnationale haïtienne. Revue Européenne des Migrations Internationales, v. 20, n. 3, p. 127-146, 2004.

AUDEBERT, C. La diaspora haitienne. Territoires migratoires et réseaux. Rennes: Éditeur Presses universitaires de Rennes, 2012.

BAPTISTE, C. J.; VIEIRA, J. M. Catástrofe ambiental e migração internacional: a perspectiva dos migrantes haitianos na cidade de São Paulo. In: BAENINGER, Rosana et al (Org.). Imigração Haitiana no Brasil. Jundiaí: Paco Editorial, 2016.

BASTIDE, R.; MORIN, F.; RAVEAU, F. Les Haïtiens en France. Paris: Ed. Mouton - la Haye, 1974.

BERNARDES, P. H. D. A. A apatridia dentro do regime interamericano de direitos humanos: o caso de dominicanos de ascendência haitiana. II Simpósio Internacional Pensar e Repensar a América Latina [Anais...]. São Paulo, 2016. p. 1-14.

BOUCARD, A. La Communauté Haitienne de Montréal. Laval, Québec: La Fondation littéraire Fleur de Lys, 2006.

CALMONT, A. Les Haïtiens en Guyane: une communauté en voie d'intégration?. In: Espace, populations, sociétés, p. 427-434, 1993.

CHARRY, L. Todos giran. Avianca em revista. Set. 2017, p. 88-89.

DORINO, A. En vue de l'action: Portait de la Communauté Haïtienne au Québec. Document du SJRM de la Province de Canada Français, 2009.

FAGEM, P. W. et al. Haitian diaspora associations and their investments in basic social services in Haiti. Georgetown University, 2009.

FERNANDES, D. (Coord.). Projeto "Estudos sobre a Migração Haitiana ao Brasil e Diálogo Bilateral”. Belo Horizonte: TEM/IOM-IOM/PUC Minas/ Gedep, 2014.

GLICK-SCHILLER, N. et al. ALL IN THE SAME BOAT? Unity and Diversity in Haitian Organizing. Caribbean Life in New York City. New York, p. 167-184, 1987.

GRONDIN. M. Haiti: cultura, poder e desenvolvimento. São Paulo: Ed. Brasiliense, 1985.

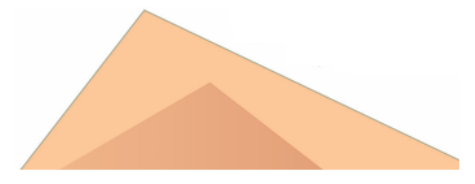


ICART, J.-C. Le Québec et Haïti: Une histoire ancienne. Cap-aux-Diamants 79, 2004. p. 30-34.

JACKSON, R. O. The uses of diaspora among Haitians in Boston. In: JACKSON, Regine O. Geographies of the Haitian Diaspora. New York: Routledge, 2011. p. 135-162.

JACQUES, Ermitte St. Between Periphery and Center in the haitian Diaspora. In: JACKSON, Regine O. Geographies of the Haitian Diaspora. New York: Routledge, 2011. p. 91-110.

JESUS, A. D. de. Fronteiras e atravessamentos: experiências migratórias de haitianos em Tijuana, México. Formação (Online), v.26, n.49, p. 85-105, 2019.

JESUS, A. D. de. Redes da migração haitiana no Mato Grosso do Sul. Tese (Doutorado em Geografia). Dourados: Universidade Federal da Grande Dourados, 2020. 313p.

JOSEPH, H. Diaspora. As dinâmicas da mobilidade haitiana no Brasil, no Suriname e na Guiana Francesa. Tese (Doutorado em Antropologia Social), UFRJ/Museu Nacional. Rio de Janeiro, 2015. 430p.

LAETHIER, M. The role of Suriname in Haitian migration to French Guyana. Identities on the move and border crossings. In: E. B. Carlin, I. Léglise, B. Migge, P. Tjon Sie Fat (eds), In and out of Suriname: language, mobility and identity. Brill, Leiden Boston, 2015. p. 229251.

MACHADO, J. Haití está en Venezuela. Solidariedade Social, p. 82-84, 2010.

MACHADO, M. R.; LORES, D. N. La inmigración haitiana hacia Guantánamo. Principales aportes culturales. Revista Caribeña de Ciencias Sociales, p. 1-8, 2014.

MACHE, Y. C.; LIMONTA, I. H. El vodu. Su impronta en la cultura religiosa cubana. Buenos Aires: CLACSO, 2007.

MAGALHÃES, L. F. A.; BAENINGER, R. Imigração haitiana no Brasil e remessas para o Haiti. In: BAENINGER, Rosana et al (Orgs). Imigração Haitiana no Brasil. Jundiaí: Paco Editorial, 2016.

MALEMBE. Inmigración hatiana a Cuba. 2013. Disponível em: https://mayombe.net/2013/01/12/inmigracion-haitiana-a-cuba/ Acesso feito em 21/09/2017. 
MARTÍNEZ, S. The onion of oppression: haitians in the Dominican Republic. In: JACKSON, R. O. Geographies of the Haitian Diaspora. New York: Routledge, 2011. p. 51-70.

MENINO, T. Imagine all the people: Haitian immigrants in Boston. City of Boston, 2009.

MIRANDA, B. Movilidades haitianas en el corredor Brasil-México: efectos del control migratorio y de la securitización fronteriza. PERIPLOS, Revista de Investigación sobre Migraciones, v. 5, n. 1, p. 108-130, 2021.

MOONEY, M. Mediating Institutions and the Adaptation of Haitian Immigrants in Paris. In: JACKSON, Regine O. Geographies of the Haitian Diaspora. New York: Routledge, 2011. p. 113-134.

NIETO, C. Migración haitiana a Brasil: redes migratorias y espacio social transnacional. $1^{\mathrm{a}}$ ed. Buenos Aires: CLACSO, 2014.

PICHARDO, H. Documentos para la historia de Cuba. V. 2. La Habana: Editorial Ciencias Sociales, 1973.

PRIMÉ, J. De l'immgration haitienne em France: historique, causes et types. 2013. Disponível em: http://jamesonprimeup.over-blog.net/de 1\%E2\%80\%99immigrationha\%C3\%AFtienne-en-france-historique-causes-et-types Acesso feito em 18/09/2017.

REVUELTA, L. Azúcar amargo: el 'apartheid' dominicano que sustenta la industria de la caña. Espanha: El Confidencial, 2017. Disponível em: https://www.elconfidencial.com/mundo/2017-0728/bateyes-republica-dominicana-haiti-inmigracion-racismo-negocio-azucarero_1413985/ Acesso feito em 29/09/2017.

ROBLES, F. Onde os haitianos não são bem-vindos. Gazeta do Povo, 2015. Disponível em: http://www.gazetadopovo.com.br/mundo/onde-os-haitianos-nao-sao-bem-vindosejrq6dvxckun9vb2osiw8d1zi Acesso feito em 07/10/2017.

STEPICK, A. The refugees nobody wants: Haitians in Miami. In: GRENIER, G.; STEPICK, A. (Orgs.). Miami Now! Immigration, Ethnicity and Social Change. Gainesville: University Press of Florida, 1992. p. 57-80.

TÉLÉMAQUE, J. Imigração haitiana na mídia brasileira: entre fatos e representações. Monografia (Graduação em Comunicação Social) UFRJ. Rio de Janeiro, 2012.

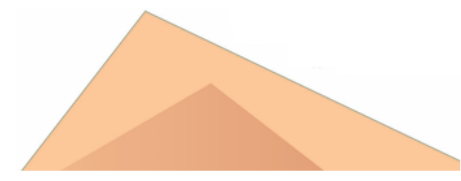


VERNA, C. F. Haitian Migration and Community-Building in Southeastern Michigan, 19661998. In: JACKSON, R. O. Geographies of the Haitian Diaspora. New York: Routledge, 2011, p. 163-184.

WOODING, B; MOSELEY-WILLIAMS, Richard. Inmigrantes haitianos y dominicanos de ascendencia haitiana en la República Dominicana. Santo Domingo: Cooperación Internacional para el Desarrollo (CID) y el Servicio Jesuita a Refugiados y Migrantes (SJR), 2004.

Recebido em setembro de 2020.

Revisão realizada em março de 2021.

Aceito para publicação em novembro de 2021. 